\title{
The journey continues
}

$\mathrm{T}$ he first issue of the Canadian Journal of Gastroenterology was published in October 1987. The brainchild of its founding co-editors, Drs ABR Thomson and CN Williams, working with Robert Kalina, the Journal's publisher, the Journal was initially not indexed and had no official affiliation with any professional organization. Over the years, through the continued efforts of its founding co-editors, the Journal continued to gain acceptance and popularity, becoming indexed in EMBASE, Medline and PubMed Central, among others, and enjoying official journal status with the Canadian Association of Gastroenterology (CAG) and, later, the Canadian Association for the Study of Liver (CASL). In recognition of the growing hepatology audience, last year, the Journal changed its name to the Canadian Journal of Gastroenterology and Hepatology (CJGH).

Now, 28 years after its founding, the Journal enters yet another new era with its fifth editorial leadership administration. Accepting the appointment of new Co-Editors-in-Chief is a significant challenge and is certainly something that we are not taking lightly. Our predecessors, Drs ABR Thomson and CN Williams, Dr Lloyd Sutherland, Dr Paul Adams and Dr Subrata Ghosh, whom we salute for the excellent precedent that they have created, have 'set the bar', as well as the expectations of both readership and submitting authors, very high. We intend to maintain the legacy that our past Editors-in-Chief have left us and sustain its momentum. Having worked our ways up the ranks of the CJGH from Editorial Board members and then Associate Editors appointed by Dr Paul Adams, followed by Deputy Editors appointed by Dr Subrata Ghosh, we have learned to accept the duality of the CJGH, which itself is nothing unique to Canadians, who are used to two official languages, as well as the perpetual debate of federal versus provincial. The Journal must not only serve the interests of CAG and CASL, but also balance the academic interests of the university community, for whom a strong impact factor is desired, with the needs of the larger community practitioners, who require pragmatic articles that can be incorporated into day-to-day clinical practice. To this end, we will continue the policies of our past mentors, Paul Adams and Subrata Ghosh: we will publish original research, but it must be clinically relevant, and we will continue to solicit timely review articles and rigorous clinical practice guidelines. We aspire to the timely review of submissions, and to rapid dissemination of key content through diverse and innovative channels. Finally, although we serve the Canadian gastroenterology and hepatology communities, we also aspire to serve the larger international community, and will continue to review and accept strong, quality manuscripts from outside of Canada.

In closing, our friend and colleague, Dr Sam Lee of the University of Calgary (Calgary, Alberta) and the past Editor-in-Chief of Liver International, always incorporated an illuminating poetic quotation in his editorials. We are not as literate but a modified quote from the late Lt Col John McCrae MD, written 100 years ago on the battle fields of Europe during the 'Great War', and famously inscribed on the walls of the dressing room of le Club de hockey Canadien (Montreal) since 1953, seems appropriate:

$$
\text { To you....we throw the torch, be yours to hold it high }
$$

We will carry the torch with pride.

Eric M Yoshida MD MHSc FRCPC FCAHS FAASLD Division of Gastroenterology, University of British Columbia, Vancouver, British Columbia

John K Marshall MD MSc FRCPC AGAF Division of Gastroenterology and Farncombe Family Digestive Health Research Institute, McMaster University, Hamilton, Ontario 


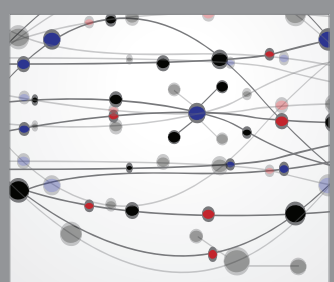

The Scientific World Journal
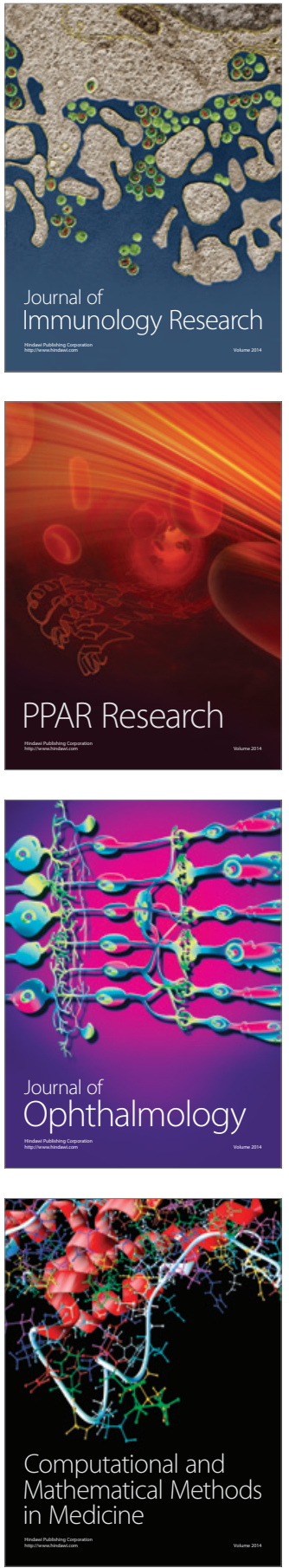

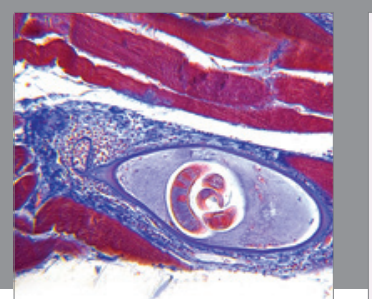

Gastroenterology Research and Practice

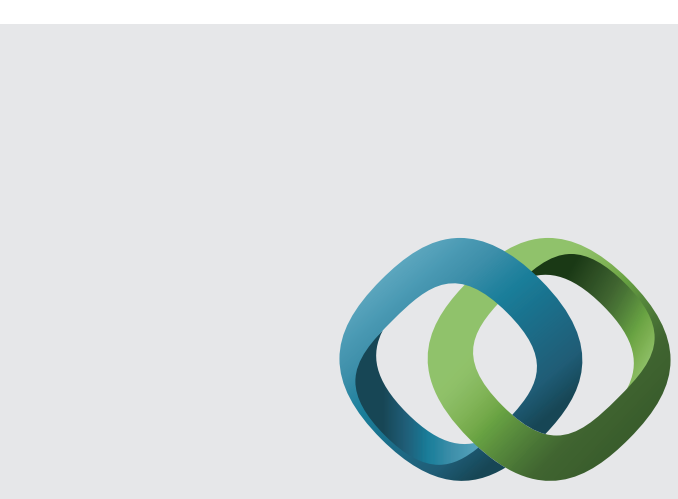

\section{Hindawi}

Submit your manuscripts at

http://www.hindawi.com
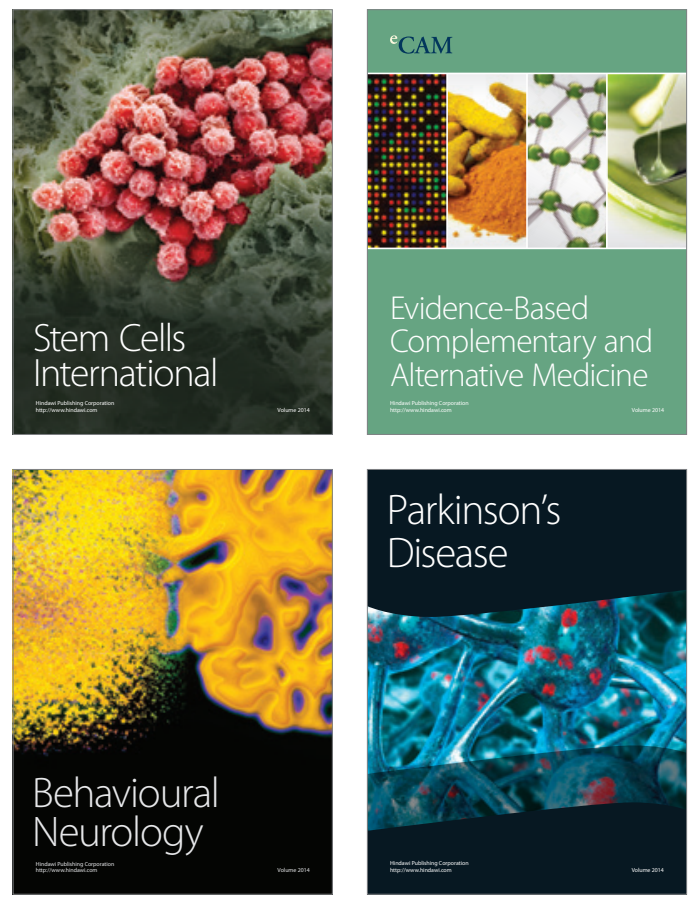
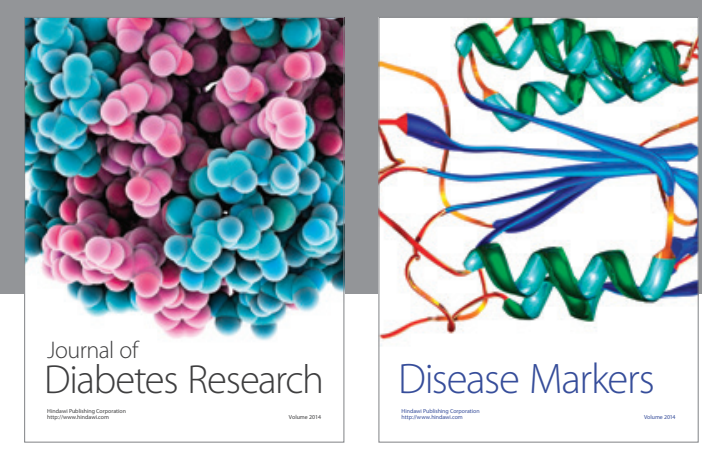

Disease Markers
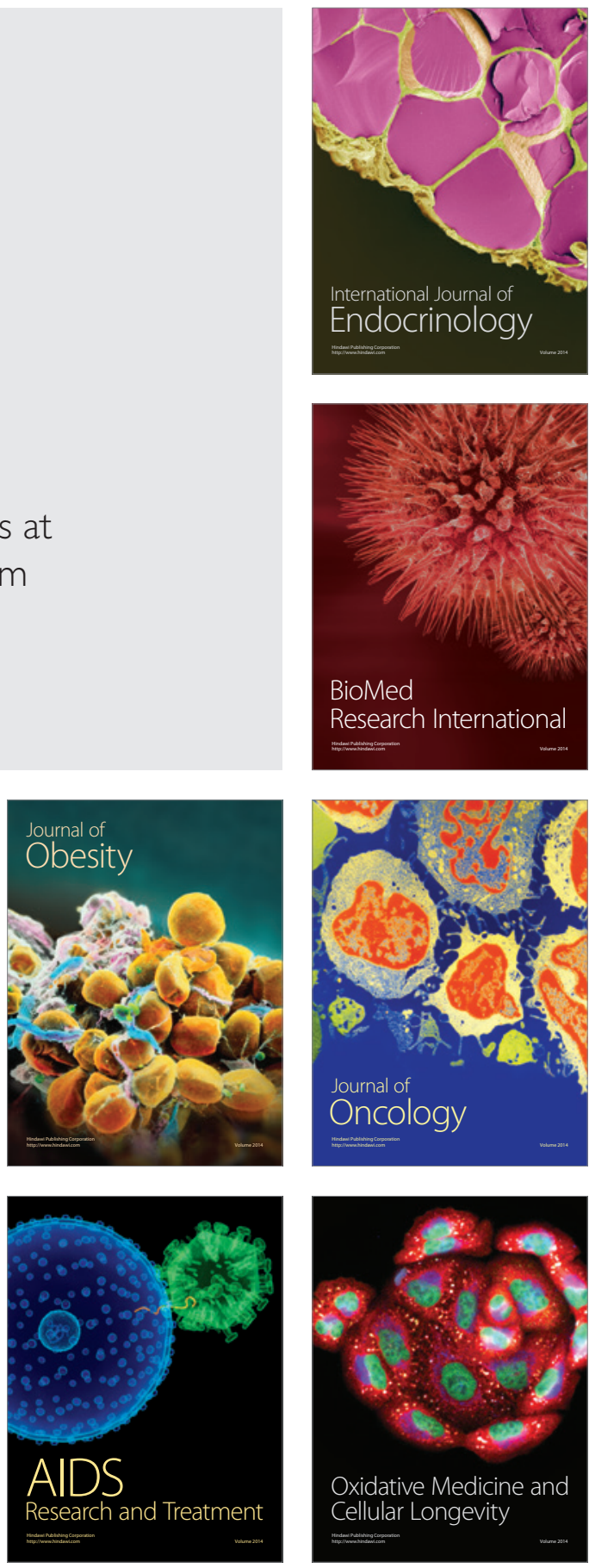